\title{
Beta Thalassemia Major
}

National Cancer Institute

\section{Source}

National Cancer Institute. Beta Thalassemia Major. NCI Thesaurus. Code C129699.

The most severe form of beta thalassemia that is characterized by the lack of functional beta-globin chain production resulting in the absence of hemoglobin $A$. 